\title{
Conciencia turística de los pobladores del Asentamiento Humano Primavera para la protección y preservación de Lomas de Primavera, Carabayllo, Lima
}

\section{Tourist amareness of the residents of the Primavera Human Settlement for the protection and presenvation of the Lomas de Primavera, Carabayllo district, Peru}

\author{
Heber Luis Olavarria Benavides* \\ Universidad de San Martín de Porres, Perú \\ Jackelyn Fernández Tello \\ Universidad Privada del Norte, Perú \\ Percy Ronald Ventura Suclupe \\ Universidad Nacional Pedro Ruiz Gallo, Perú
}

\section{RESUMEN}

Lomas de Primavera es un recurso natural atractivo para el turismo y la investigación. Se ubica en el distrito de Carabayllo, al norte de Lima, con una extensión de 1700 hectáreas; gracias a su espacio abierto con bellos paisajes, biodiversidad, fauna, flora, riqueza histórica y arqueológica tiene valor turístico y cultural, por lo que su desarrollo debe darse de manera sustentable y sostenible. Por lo tanto, es importante determinar la conciencia turística de los pobladores del Asentamiento Humano Primavera con respecto al recurso natural Lomas de Primavera, ya que son los llamados a participar en su protección y preservación. La exploración se hace en función de tres categorías: conocimiento, valores y actitudes. La investigación tiene un enfoque cualitativo y su diseño es fenomenológico; la muestra está integrada por 35 pobladores y la técnica utilizada es la entrevista. Además de la presentación del marco teórico y la participación de instituciones, se muestran resultados y recomendaciones.

Palabras clave: conciencia, turismo, conocimiento, valores, actitud.

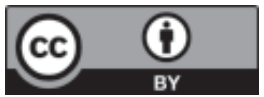




\begin{abstract}
Lomas de Primavera is a natural resource, attractive for tourism and research. It is located in the Carabayllo district, north of Lima, with an area of 1700 hectares. Thanks to its open space with beautiful landscapes, biodiversity, fauna, flora, historical and archaeological resources, it has tourist and cultural value, so its development must be sustainable. Therefore, it is important to determine the tourist awareness of the inhabitants of the Primavera Human Settlement regarding Lomas de Primavera as a natural resource, since they must participate in its protection and preservation. The exploration is done based on three categories: knowledge, values and attitudes. The research has a qualitative approach, and its design is phenomenological; the sample is made up of 35 residents and the technique used was the interview. In addition to the presentation of the theoretical framework and the participation of institutions, results and recommendations are shown.
\end{abstract}

Keywords: awareness, tourism, knowledge, values, attitude.

\title{
Introducción
}

La conciencia turística es un pilar importante para el desarrollo del turismo, por lo tanto, es fundamental que los ciudadanos, prestadores de servicios, autoridades, turistas y visitantes locales comprendan los efectos y consecuencias de las actividades turísticas en cada lugar, ya que tomar conciencia permite alcanzar un desarrollo sustentable y sostenible de los destinos turísticos. Para lograrlo es necesario activar la conciencia turística en aspectos como el aprecio por la comunidad, el patrimonio turístico y la educación; también, poseer un alto espíritu y mística de servicio, excelente trato con las personas y mucha disciplina. En resumen, de acuerdo a Ramírez (1994), en el proceso de concientización turística se requiere alto sentido de responsabilidad, dedicación, honestidad, cortesía y amabilidad.

Por otra parte, la conciencia ambiental, es un elemento importante en el desarrollo de la actividad turística dentro de un recurso natural, ya que promueve y genera comportamientos en favor del medioambiente, así como determinados valores y actitudes (Cabana, 2017).

En este sentido, la Organización Mundial del Turismo (OMT, 2017) puso en marcha la campaña internacional "Viaja, disfruta y respeta”, con el objetivo de crear conciencia turística por el valor y contribución del turismo sostenible para el desarrollo de los pueblos y cuidado del medioambiente. Algunos países, como Chile, en las ciudades de Arica y Parinacota, desarrollaron estrategias de turismo, sobre la base de cinco pilares: "promoción, sustentabilidad, inversión y competitividad, calidad y capital humano, e inteligencia de mercado" (Servicio Natural de Turismo [SERNATUR], 2013, p. 2); asimismo, en 2016, su informe de gestión da cuenta de charlas de capacitación en conciencia turística brindada a empresarios del sector costero, estudiantes y dirigentes sociales encargados del cuidado del patrimonio (SERNATUR, 2016).

El Perú, mediante el Ministerio del Ambiente (MINAM) ejecutó el Programa Municipal EDUCCA(Educación, Cultura y Ciudadanía Ambiental) con el objetivo de promover procesos participativos en educación y cultura 
ambiental entre la ciudadanía, siendo consecuentes con el crecimiento continuo del turismo durante el periodo del 2011-2015 (Ministerio de Comercio Exterior y Turismo [Mincetur], 2016, 2019). Este motor de desarrollo social y económico, capaz de contribuir a la inclusión social y la reducción de la pobreza, debe recuperarse y ampliarse una vez superada la crisis por la pandemia que ha modificado sustancialmente la vida, la salud, la economía y otras áreas, particularmente el traslado de las personas afectando principalmente al turismo.

La conciencia turística, por lo tanto, cumple un rol fundamental frente al cambio climático y el cuidado de espacios naturales, muy requeridos en esta «nueva normalidad». No obstante, son también espacios vulnerables desde hace mucho tiempo. Una iniciativa para la protección de las lomas es el proyecto «Conservación, gestión y rehabilitación de los ecosistemas frágiles de lomas», EbA Lomas (Programa de las Naciones Unidas para el Desarrollo [PNUD], 2017).

Precisamente, Lomas de Primavera es un recurso natural atractivo para el turismo y la investigación, gracias a que es un espacio abierto con bellos paisajes, biodiversidad de especies y riqueza arqueológica e histórica. Para protegerlo se deben considerar sus características y necesidades.

Como es conocido, el cielo limeño durante el invierno se cubre de neblinas cargadas de humedad que impiden el paso de los rayos del sol (por eso algunos la llaman Lima la gris), estas, se precipitan bajo la forma de garúa. Se produce un ecosistema único y especial en las lomas, beneficiando el crecimiento de vegetación que reverdece con la humedad (PNUD, 2018). La mayor contribución, de Lomas de Primavera, son los servicios ecosistémicos: servicio de provisión, servicio de regulación y servicio cultural (Figura 1). Los ecosistemas, en épocas de verdor, permiten la alimentación, descanso y reproducción de diversas especies. Su cercanía a la ciudad, su estado de conservación y su representatividad resultan útiles para la investigación sobre biología y ecología. Tiene potencial como centro de educación ambiental y de turismo asociado a la naturaleza e historia, ya que guarda importantes evidencias arqueológicas.

Figura 1

Servicios ecosistémicos de Lomas de Primavera

\begin{tabular}{|l|ll|}
\hline $\begin{array}{l}\text { Servicio de } \\
\text { Provisión }\end{array}$ & $\begin{array}{l}\text {-captación de agua atmosferica } \\
\text {-provisión de recursos } \\
\text { genéticos y de alimentos }\end{array}$ \\
\hline $\begin{array}{l}\text { Servicio de } \\
\text { Regulación }\end{array}$ & $\begin{array}{l}\text {-La polinización: } \\
\text {-Purificación del aire }\end{array}$ \\
\hline Servicio Cultural & $\begin{array}{l}\text { •Educacional } \\
\bullet \text { recreativos y de ecoturismo } \\
\text { •Estéticos }\end{array}$ \\
\hline
\end{tabular}

Nota. Datos de Proyecto EbA Lomas. 
Lomas de Primavera, es un recurso natural ubicado en el distrito de Carabayllo, al norte de Lima. Su extensión es de 1700 hectáreas; aquí se pueden encontrar 102 especies de flora y aproximadamente 39 especies de fauna: aves, insectos, reptiles, entre otros (PNUD, 2017). También, se hallan importantes evidencias arqueológicas como geoglifos, petroglifos y se aprecia el famoso colchón de nubes.

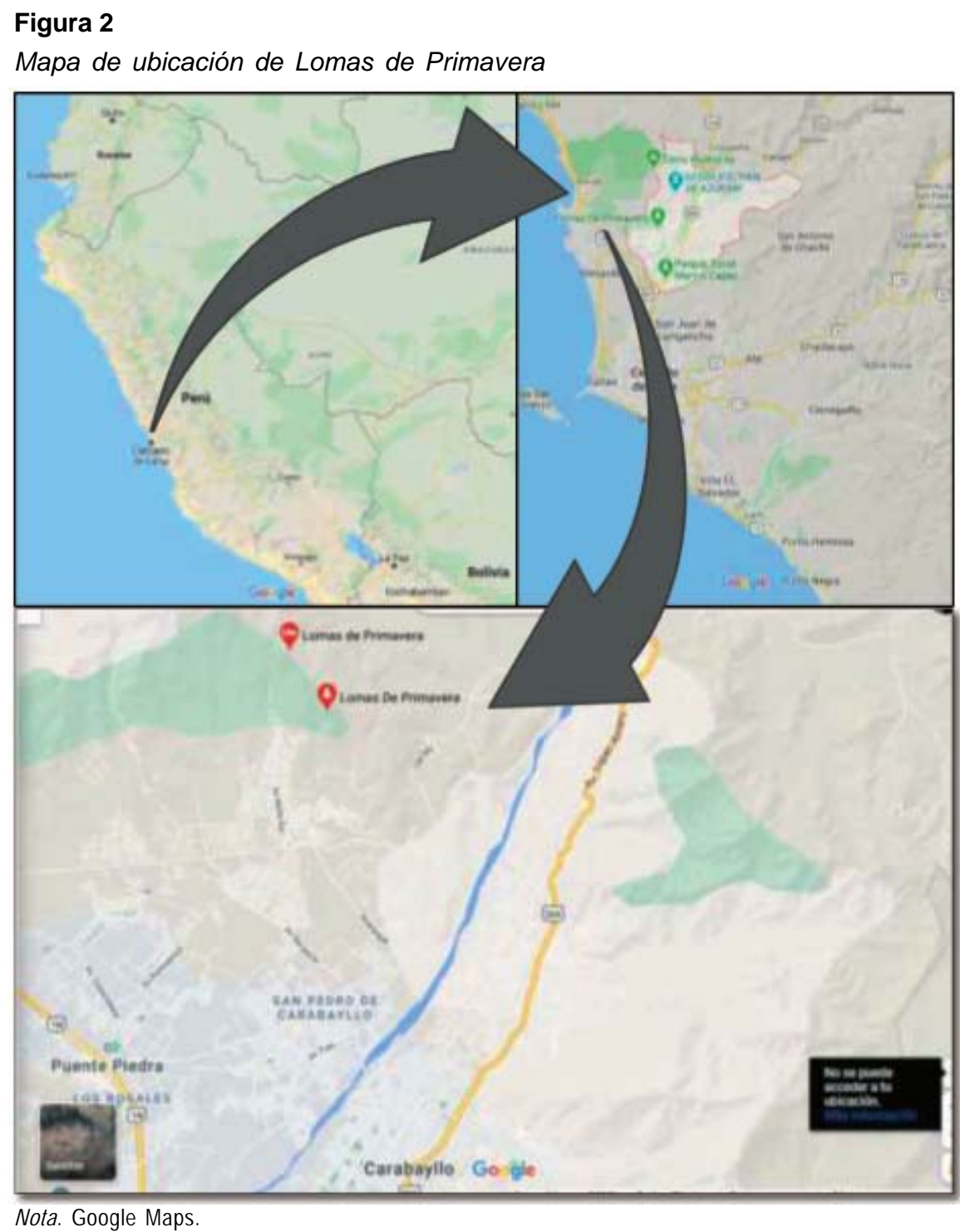

Por lo descrito, es necesario desarrollar la conciencia turística en estas lomas debido a las amenazas múltiples, como la minería informal para la extracción de agregados de la construcción, las invasiones, el tráfico de terrenos, la constante ampliación de algunos asentamientos ya consolidados y la pérdida de biodiversidad y el espacio de estos ecosistemas. Concerniente a ello, el señor Ascencio Vásquez, presidente de la Asociación 
ecológica Lomas de Primavera en 2019 (al ser entrevistado por los investigadores), remarcó que en 2016 y 2017 las lomas sufrieron siete invasiones, afortunadamente desalojadas finalmente. Por eso y más amenazas, es necesario protegerlas. Incluso, puede ser fuente de ingreso para los pobladores del lugar encargados de su cuidado.

Es así que, conjuntamente con la Municipalidad de Carabayllo, se tomaron acciones para recuperar y mantener Lomas de Primavera. Se aprobó la Ordenanza N. ${ }^{\circ} 1651$ del Plan Específico de Lomas de Primavera, que contiene la zonificación y reglamentación especial; parámetros urbanísticos y edificaciones, así como, índice de usos para la ubicación de actividades urbanas y la modificación del sistema vial metropolitano.

$\mathrm{Al}$ respecto, en el año 2016, los municipios en Lima que tienen lomas sumaron esfuerzos, es el caso de la Ordenanza Municipal del distrito de Independencia N. ${ }^{\circ}$ 345-2016-MDI, que declara de interés distrital la intangibilidad, de interés patrimonial-cultural y de protección paisajística al ecosistema frágil denominado «Loma de Amancaes - Bella Durmiente». Por su parte, la Municipalidad de Carabayllo, en 2018, mediante Ordenanza Municipal N. ${ }^{\circ}$ 397-2018-MDC declara de interés distrital la intangibilidad, de interés patrimonial-cultural y de protección paisajística al ecosistema frágil denominado Lomas de Primavera o Lomas de Carabayllo. En esa ruta, el Programa de las Naciones Unidas para el desarrollo, mediante la ONU Voluntarios y sus proyectos DIPECHO y EbA Lomas, en alianza estratégica con la Municipalidad de Carabayllo, llevaron a cabo la feria y caminata con el lema «Hogar Natural al Asentamiento Humano Primavera» con la finalidad de sensibilizar e incidir sobre la importancia de proteger estos espacios naturales en Lima Metropolitana (PNUD, 2017).

Cabe destacar que, el distrito de Carabayllo, es uno de los distritos del departamento de Lima conocido por tener recursos suficientes para consolidar una oferta turística. Además de la reserva natural Lomas de Primavera, se encuentran la Hacienda Punchauca, la Casa Hacienda El Fortín y otros.

Por consiguiente, se plantea como objetivo determinar la conciencia turística de los pobladores del Asentamiento Humano Primavera para la protección y preservación del recurso natural Lomas de Primavera, en función de tres categorías: conocimiento, valores y actitudes. La entrevista a 35 participantes se circunscribe a nueve códigos (1) Conocimiento de la importancia del recurso natural, (2) Conocimiento de la problemática del lugar, (3) Importancia del turismo, (4) Responsabilidad del recurso natural, (5) Respeto al turista, (6) Honestidad, (7) Compromiso, (8) Preservación, (9) Conservación.

\section{Marco teórico}

\section{Conciencia ambiental}

La conciencia ambiental es un tema escasamente explorado y tratado en contextos socioeducativos. Es un término que se ha acuñado «para definir el conjunto de imágenes y representaciones que tienen como objetivo de atención al medio ambiente» (Díaz y Fuentes, 2017). La conciencia ambiental incluye procesos asociados de forma multidimensional que constituye la dimensión actitudinal del comportamiento en favor del medioambiente (Tonello y Valladares, 2015). 


\section{Conciencia turística}

La conciencia turística apunta a promover e incrementar la preservación del patrimonio y servicios que posee una comunidad, región o distrito. Así lo considera Mireles (2015, p. 42), al señalar que «la conciencia turística es una reflexión o filosofía que tiene como base la disposición de tratar de manera amable a los turistas, así como la difusión de cuidar los bienes que tiene cada pueblo».

\section{Conciencia social}

Conciencia social es la capacidad propia de los seres humanos para percibir, reconocer y comprender los problemas y las necesidades que tienen las personas de una determinada comunidad, entidad, grupo social o tribu. Ser consciente también implica analizar, reflexionar y tomar postura, en conjunto, frente a los problemas, teniendo en cuenta que lo que afecta a cualquier miembro de la estructura social tiene un impacto directo en los demás, tanto negativo como positivo (Alto Comisionado de las Naciones Unidas para los Refugiados [UNHCR], 2016).

\section{Conciencia en el Perú}

El orgullo, el regionalismo y la peruanidad son elementos a los que el turismo convierte en valores reales y tangibles. Por ello, es importante involucrar a todas las personas a nivel local, regional y nacional desde las aulas. De acuerdo a La Riva (2017) el conocimiento de la ciudad, sus tradiciones y costumbres del país en general son el sustento para sentir orgullo y eso lo provee el turismo como vehículo cultural. Es así que el orgullo nacional y conciencia turística forman parte de un proceso educativo de gran escala en el que ambos corren juntos.

\section{Conocimiento}

El conocimiento es la acción de conocer o recibir información valiosa para entender la realidad por medio de la razón, el entendimiento y la inteligencia. El conocimiento es tener una idea sobre la herencia que pertenece a una población; es decir, saber, conocer o respetar sus tradiciones, costumbres y la cultura que se desarrolla debe ser conservada y transmitida a los próximos pobladores de dicho lugar (Molano, 2007). Implica reconocer la trascendencia de los colectivos para que se hagan sistemáticos los campos y las líneas de investigación del turismo (Tobar et al., 2015).

\section{Valores}

Según la ética, el concepto de valoración se refiere a un establecido juicio que cada acto tiene a los ojos de un sujeto o de la sociedad. En este sentido, la valoración de los recursos culturales forma parte de la afinidad de uno mismo, debido a que se trata de defender, recuperar, proteger, vigilar y custodiar los bienes culturales que dejaron como legado los antepasados, para ser apreciados o estimados por todos los habitantes y ser transmitidos a los descendientes. 
La valoración de las singularidades locales por medio de los pobladores hace atractiva la localidad desde el punto de vista turístico, ya que propicia la producción de bienes culturales diferenciados, el consumo de mercaderías con calidades específicas y el surgimiento de nuevas modalidades de servicios como las volcadas al uso turístico (Ciliane et al., 2014).

\section{Actitudes}

La actitud positiva con los turistas es un factor importante porque se evidencia la voluntad, el deseo o anhelo y las ganas de brindar un servicio eficiente, sin discrepancias ni inconvenientes entre los clientes. La conducta positiva ayuda a resolver las dudas o problemas, haciendo que los reclamos se controlen en un ambiente positivo y tranquilo; de tal modo que los consumidores sientan que su reclamo es escuchado y tomado en cuenta con formalidad y seriedad (Bellido, 2017).

$\mathrm{Al}$ respecto, Mendoza et al. (2013) señalan que si la actitud se considera mediadora entre los estímulos externos y las respuestas o reacciones de las personas frente a un ambiente, esto es una forma de adaptación activa de la persona a su medioambiente. Para la obtención de un desarrollo turístico debe existir una comprensión de la percepción local, sumado a la seguridad y los elementos de comodidad, que influyen tanto en los visitantes como en los lugareños (Mendoza et al., 2018).

Además, sostienen Díaz y Gutiérrez (2010), que la actitud del residente debe formar parte de los procesos de planificación de los destinos, pues su predisposición favorable o no puede afectar la experiencia del turista, el eje de comunicación del destino, así como la satisfacción del visitante.

\section{Recurso natural}

Los conceptos de recurso natural, en disciplinas como la geografía y economía, se refieren a una determinada propiedad del medio que atraviesa un proceso de evaluación. Desde la definición antropocéntrica los recursos naturales se consideran una función de las capacidades humanas e implica, como es obvio, una consideración histórica de los recursos (Urteaga, 1999).

Con relación a la función de los recursos naturales Orellana y Lalvay (2018) sostienen:

Los recursos naturales son aprovechados por el ser humano para satisfacer sus necesidades de subsistencia, tales como alimentación, salud, económicas y de ocio; éstos se han convertido en una fuente de vida y desarrollo para la comunidad que habita en este lugar. En el momento que el hombre hace uso de estos recursos no solo obtiene beneficios personales, sino también ayuda a que la comunidad tenga un mejor desarrollo local y turístico.

Cabe resaltar que el turismo es una vía privilegiada para hacer efectiva esta necesidad de conocer la naturaleza y contribuir, con ello, tanto a su preservación como al enriquecimiento personal. También, y contra lo que suele argumentarse, es una vía para reincorporarla a los circuitos económicos y a la dinámica social general (Bertoncello y Troncoso, 2018). 


\section{Conservación}

La conservación, de acuerdo a Ferrero (2018), «se presenta como un proceso político y social por el cual se manejan los recursos naturales para mantener procesos ecológicos. Por lo tanto, consideramos que el vínculo con las poblaciones locales se define en las interacciones y arenas políticas locales».

\section{Metodología}

La presente investigación tiene un enfoque cualitativo y su diseño es fenomenológico. Como lo establecen Hernández et al. (2014), el propósito es explorar, descubrir y comprender las experiencias de las personas con respecto a un fenómeno, descubriendo elementos en común de tales vivencias. El diseño de muestreo es un subgrupo seleccionado que representa a la población (Baena, 2017). Integran la muestra 35 pobladores del Asentamiento Humano Primavera. La técnica seleccionada es la entrevista; para los efectos de la misma, se consideraron nueve códigos con su respectiva descripción (Tabla 1).

Tabla 1

Relación de códigos

Códigos Descripción

1. Conocimiento de la importancia del recurso natural

2. Conocimiento de la problemática del lugar

3. Importancia del turismo

4. Responsabilidad del recurso natural

5. Respeto al turista

6. Honestidad

7. Compromiso

8. Preservación

9. Conservación
El conocimiento de la importancia que tienen los pobladores hacia el recurso natural Lomas de Primavera.

Conocimiento de los pobladores sobre los problemas que se suscitan en las Lomas de Primavera.

La importancia del turismo en las Lomas de Primavera.

La responsabilidad que sostienen los pobladores con las Lomas de Primavera.

Respeto que tienen los pobladores con el turista que visita las Lomas de Primavera.

La honestidad que poseen los pobladores.

El compromiso con el recurso natural de parte de los pobladores del Asentamiento Humano Primavera.

Preservación del patrimonio natural por parte de los pobladores del Asentamiento Humano Primavera.

Si los pobladores del Asentamiento Humano Primavera practican una buena conservación del recurso.

El análisis cualitativo de la conciencia turística, más que en el tamaño de la muestra, se centró en la riqueza de la información vertida por los participantes en función de tres categorías: conocimiento, valores y actitudes (Figura 3). 


\section{Figura 3}

Categorías para la descripción de la conciencia turística

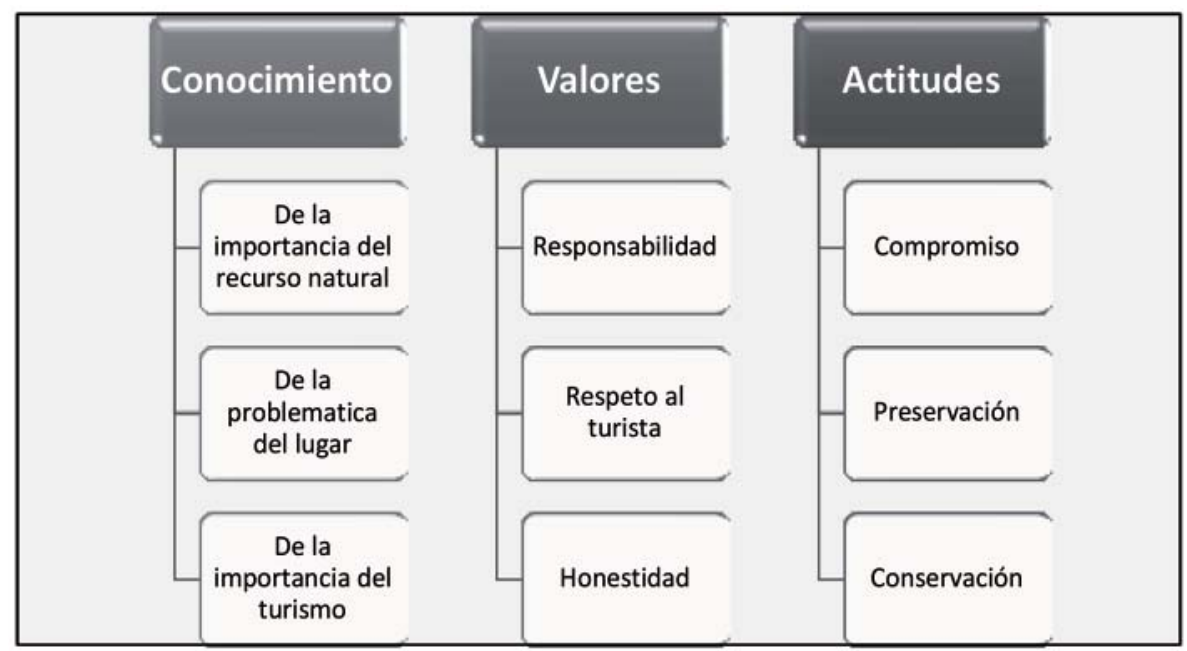

\section{Resultados}

Los pobladores del Asentamiento Humano Primavera demuestran conciencia turística respecto del recurso natural Lomas de Primavera, ubicado en el distrito de Carabayllo, Lima, Perú.

\section{Conocimiento}

Los pobladores del Asentamiento Humano Primavera reconocen la importancia y trascendencia que tiene el recurso o atractivo natural Lomas de Primavera. Sus experiencias con los grupos de visitantes, de diferentes edades, nivel económico, cultural, etc. los han conducido a valorar el lugar y entender que el desarrollo de Lomas de Primavera debe ser sustentable y sostenible, no solo para ellos mismos, sino también para turistas o visitantes atraídos por diversas motivaciones.

Asimismo, están informados y vivencian problemas y amenazas, tales como abandono, falta de concientización, tráfico de terrenos, contaminación y muchos más. Frente a estos desafíos toman acciones en coordinación con organismos gubernamentales e instituciones como la Municipalidad de Carabayllo, Proyecto EbA Lomas, Red de lomas del Perú, EMPROTUR (Emprendimiento y promoción turística UNMSM), Ministerio de Cultura y otros (PNUD, 2017). Del mismo modo, promueven la obtención de ingresos económicos gracias a las visitas con la finalidad de alcanzar bienestar social, cultural y ambiental.

En la Tabla 2 se muestra de manera cuantitativa la importancia de la existencia de Lomas de Primavera y los problemas que presenta este recurso natural. La muestra es clasificada según el sexo ( $\mathrm{F}=$ femenina y $\mathrm{M}$ = masculina). Del total de la muestra (35 entrevistados), 18 corresponden al sexo femenino y 17 al sexo masculino. Como problemática mayor de las Lomas de Primavera, 17 pobladores, señalan tráfico de 
terreno; 8 pobladores señalan abandono, traducido en descuidado, falta de mantenimiento, etc.; 5 pobladores señalan contaminación; 2 pobladores señalan falta de conciencia turística o concientización; y 3 de ellos no saben o no conocen alguna problemática.

Sobre la importancia de la existencia de Lomas de Primavera: 13 personas indican importancia de nivel ambiental, por la flora y fauna que ahí se encuentra; 12 personas indican belleza paisajística; y 10 indican importancia de la actividad turística, por la afluencia de visitantes y oportunidades de crecimiento económico para los habitantes del lugar.

\section{Tabla 2}

Importancia de la existencia de Lomas de Primavera y problemas que presenta, según la población femenina y masculina

\begin{tabular}{lcccccc}
\hline \multirow{2}{*}{$\begin{array}{l}\text { Importancia de la } \\
\text { existencia de las Lomas }\end{array}$} & \multicolumn{5}{c}{ Problemas que presenta las Lomas de Primavera } \\
\cline { 2 - 7 } & Abandono & Concientización & Contaminación & No sabe & Tráfico de terrenos & Total \\
\hline F & $\mathbf{4}$ & $\mathbf{1}$ & $\mathbf{3}$ & $\mathbf{2}$ & $\mathbf{8}$ & $\mathbf{1 8}$ \\
Ambiental & 1 & 1 & 1 & 1 & 2 & 6 \\
Belleza paisajística & 3 & & 1 & 1 & 2 & 7 \\
Turística & & & 1 & & 4 & 5 \\
M & $\mathbf{4}$ & $\mathbf{1}$ & $\mathbf{2}$ & $\mathbf{1}$ & $\mathbf{9}$ & $\mathbf{1 7}$ \\
Ambiental & 1 & 1 & 1 & & 4 & 7 \\
Belleza paisajística & 2 & & 1 & 1 & 1 & 5 \\
Turística & 1 & & & & 4 & 5 \\
\hline Total & $\mathbf{8}$ & $\mathbf{2}$ & $\mathbf{5}$ & $\mathbf{3}$ & $\mathbf{1 7}$ & $\mathbf{3 5}$ \\
\hline
\end{tabular}

En la Tabla 3 se aprecia los resultados sobre la importancia del turismo y beneficio de la actividad turística, según la población femenina y masculina, con respecto a Lomas de Primavera. Frente a la pregunta por qué cree que el turismo es importante, las entrevistadas (sexo femenino) responden: 10 = generar empleo local, 4 = mejora la calidad de vida, y 4 = se hace conocido el lugar; mientras los entrevistados (sexo masculino) responden: 7 = generar empleo local, 4 = mejora la calidad de vida, y 6 = se hace conocido el lugar.

Por otro lado, con respecto al beneficio de la actividad turística, de acuerdo a los componentes ambiental, cultural, económico y social: 10 pobladores (entre hombres y mujeres) consideran que el mayor beneficio es ambiental, por eso deben cuidar y proteger el recurso natural; 13 pobladores consideran que el beneficio es cultural, que mediante esta actividad turística pueden conocer más sobre el recurso donde se encuentran, y además tener un intercambio cultural con los visitante; 6 pobladores consideran que el beneficio es económico ya que pueden obtener ingresos; y por último, 6 pobladores consideran que el beneficio es social. 
Tabla 3

Importancia del turismo y beneficio de la actividad turística, según la población femenina y masculina

\begin{tabular}{lccccc}
\hline \multirow{2}{*}{$\begin{array}{c}\text { Importancia del } \\
\text { turismo }\end{array}$} & \multicolumn{5}{c}{ Beneficio de la actividad turística } \\
\cline { 2 - 6 } F & Ambiental & Cultural & Económico & Social & Total \\
Generar empleo local & $\mathbf{3}$ & $\mathbf{8}$ & $\mathbf{4}$ & $\mathbf{3}$ & $\mathbf{1 8}$ \\
Mejora calidad de vida & 1 & 5 & 2 & 2 & 10 \\
Se hace conocido el lugar & 1 & 2 & & 1 & 4 \\
M & $\mathbf{7}$ & 1 & 2 & & 4 \\
Generar empleo local & 4 & $\mathbf{5}$ & $\mathbf{2}$ & $\mathbf{3}$ & $\mathbf{1 7}$ \\
Mejora calidad de vida & 1 & 3 & 1 & 1 & 7 \\
Se hace conocido el lugar & 2 & 1 & 1 & 2 & 4 \\
\hline Total & $\mathbf{1 0}$ & $\mathbf{1 3}$ & $\mathbf{6}$ & $\mathbf{6}$ & $\mathbf{3 5}$ \\
\hline
\end{tabular}

Valores

Los valores de los pobladores del Asentamiento Humano Primavera se evidencian mediante el comportamiento frente a los turistas o visitantes a Lomas de Primavera. Valores como amabilidad, atención, receptividad y servicio son promovidos en charlas y diversas actividades planificadas por instituciones como la Municipalidad de Carabayllo, Proyecto EbA Lomas, Red de lomas del Perú, EMPROTUR (Emprendimiento y promoción turística UNMSM), Ministerio de Cultura y otros (PNUD, 2017).

Los resultados cuantitativos del comportamiento de los pobladores frente al turista o visitante se muestran en la Tabla 4. Al consultarle a los entrevistados sobre qué comportamientos deben mantener frente a un visitante que llegue a las Lomas de Primavera, 10 entrevistados responden ser servicial, como valor que radica en la voluntad de ayudar a quien lo necesite; también 10 entrevistados responden que deben ser receptivos, como una oportunidad para establecer relaciones interpersonales basadas en la aceptación y el respeto; 8 entrevistados responden que deben ser atentos frente al turista o visitante; y 7 entrevistados responden que deben tener el valor de la amabilidad.

Tabla 4

Comportamiento de los pobladores frente al turista o visitante

\begin{tabular}{lccc}
\hline Valores & F & M & Total \\
\hline Amable & 4 & 3 & 7 \\
Atentos & 5 & 3 & 8 \\
Receptivos & 4 & 6 & 10 \\
Serviciales & 5 & 5 & 10 \\
\hline Total & $\mathbf{1 8}$ & $\mathbf{1 7}$ & $\mathbf{3 5}$ \\
\hline
\end{tabular}




\section{Actitudes}

La conciencia turística también es definida por la categoría actitudes. Considerando que la actitud representa el sentimiento, pensamiento y comportamiento de los pobladores del Asentamiento Humano Primavera respecto del recurso natural Lomas de Primavera. Son manifestaciones de las actitudes, por ejemplo, la organización y participación en eventos los días festivos, asistir a las capacitaciones dictadas por estudiantes e instituciones especializadas en el cuidado de los recursos naturales, seguir las ordenanzas que prohíben botar y quemar basura en las calles y en las lomas, reconociendo que al hacerlo se contamina el medioambiente, perjudicando directamente a los propios pobladores, turistas y al recurso natural Lomas de Primavera.

Los resultados en la Tabla 5, evidencian las actitudes de los pobladores mediante actividades que ayudan a preservar Lomas de Primavera: 10 entrevistados (4 de sexo femenino y 6 de sexo masculino) responden no arrojando desperdicios, pues estos deterioran el recurso; también 10 (6 de sexo femenino y 4 de sexo masculino) responden con actividades de reforestación; 9 afirman su voluntad de obtener capacitaciones de la municipalidad o de los voluntarios ecologistas que van de manera periódica; y 6 entrevistados responden no dañar las plantas, pues así se ayuda a la actividad turística en este lugar.

Sobre cómo conservar la flora y la fauna de las Lomas de Primavera, 6 entrevistados indican que se lograría conociendo su importancia; 14 entrevistados indican cuidándola y protegiéndola, asumiendo ellos una responsabilidad sobre este lugar; 7 entrevistados indican que se lograría no botando residuos sólidos en las lomas; y finalmente, 8 entrevistados indican que para la conservación de la flora y fauna deben trabajar los pobladores y autoridades de manera conjunta.

\section{Tabla 5}

Actitudes de los pobladores

\begin{tabular}{|c|c|c|c|c|c|}
\hline \multirow{2}{*}{$\begin{array}{c}\text { Como conservar la flora } \\
\text { y fauna de Lomas } \\
\text { de Primavera }\end{array}$} & \multicolumn{5}{|c|}{ Actividades que ayudan a preservar las Lomas de Primavera } \\
\hline & Capacitaciones & $\begin{array}{l}\text { No arrojando } \\
\text { desperdicios }\end{array}$ & $\begin{array}{l}\text { No dañar las } \\
\text { plantas }\end{array}$ & Reforestación & Total \\
\hline $\mathbf{F}$ & 5 & 4 & 3 & 6 & 18 \\
\hline Conociendo su importancia & 1 & & & 1 & 2 \\
\hline Cuidándola y protegiéndola & 2 & 3 & 2 & 1 & 8 \\
\hline No botando residuos solidos & & 1 & 1 & 2 & 4 \\
\hline $\begin{array}{l}\text { Trabajar con pobladores } \\
\text { y autoridades }\end{array}$ & 2 & & & 2 & 4 \\
\hline M & 4 & 6 & 3 & 4 & 17 \\
\hline Conociendo su importancia & 1 & 1 & & 2 & 4 \\
\hline Cuidándola y protegiéndola & 2 & 2 & 2 & & 6 \\
\hline No botando residuos solidos & & 1 & 1 & 1 & 3 \\
\hline $\begin{array}{l}\text { Trabajar con pobladores } \\
\text { y autoridades }\end{array}$ & 1 & 2 & & 1 & 4 \\
\hline Total & 9 & 10 & 6 & 10 & 35 \\
\hline
\end{tabular}




\section{Discusión}

El conocimiento que poseen los pobladores del recurso natural es valioso, en la medida que revela la motivación, respeto y voluntad de comprometerse en la protección y preservación del recurso o atractivo natural. Los resultados son favorables y óptimos, pues un sector mayoritario de la población es consciente de los problemas y amenazas que ha soportado todavía en la actualidad soporta Lomas de Primavera. Tienen una visión realista del lugar que ocupan y asumen a las lomas como su herencia, que deben cuidar para que sobreviva y perdure para las siguientes generaciones, respetando tradiciones, costumbres y cultura. Con relación a ello, Tobar et al. (2015) sostiene que construir conocimiento, difundirlo y establecer orientaciones en torno a él implica reconocer la trascendencia de los colectivos.

En cuanto a los valores, están representados por la responsabilidad, respeto al turista y honestidad. En este caso, los representantes de la Municipalidad de Carabayllo, Proyecto EbA Lomas y Proyecto DIPECHO, son los que brindan estrategias a los pobladores para afrontar los retos. Con el conocimiento necesario asumen su rol con responsabilidad y respeto por el turista o visitante, ofreciendo servicios y productos de calidad para que se lleven una buena experiencia y, como efecto, vuelvan o lo recomienden. En este sentido, Ciliane et al. (2014), entienden que la valoración de las singularidades locales, por medio de los pobladores, hace atractiva la localidad desde el punto de vista turístico, ya que propicia la producción de bienes culturales diferenciados, el consumo de mercaderías con calidades específicas y el surgimiento de nuevas modalidades de servicios como las volcadas al uso turístico.

Respecto de las actitudes hacia las Lomas de Primavera, esta es notoria y se evidencia en el compromiso y participación de los pobladores del Asentamiento Humano Primavera en actividades como charlas de capacitación a cargo de los organismos gubernamentales y otros que dedican esfuerzos permanentes en el cuidado del medioambiente, concientizando a los pobladores y capacitándolos en temas de recursos naturales y valores culturales e históricos. El compromiso con Lomas de Primavera tiene como efecto mayor afluencia de visitas, de diversos segmentos, sobre todo de escolares.

Según lo señalan Mendoza et al. (2013) si la actitud se considera mediadora entre los estímulos externos y las respuestas o reacciones de las personas frente a un ambiente, la actitud sería una forma de adaptación activa de la persona a su medioambiente. Por consiguiente, los pobladores del Asentamiento Humano Primavera pueden adaptarse y comprometerse en el cuidado de las Lomas de Primavera.

Concerniente a lo planteado, Martínez (como se citó en Castro, 2002) afirma que la actitud se refiere a las concepciones fundamentales relativas a la naturaleza del ser humano, implica ciertos componentes morales o humanos y exige compromiso personal y se define como una tendencia o disposición constante a percibir y reaccionar en un sentido, por ejemplo, de tolerancia o intolerancia, de respeto o crítica, de confianza o de desconfianza, etc. Agregan, Díaz y Gutiérrez (2010), que la actitud del residente debe formar parte de los procesos de planificación de los destinos, pues su predisposición, favorable o no, puede afectar la experiencia del turista, el eje de comunicación del destino y la satisfacción del visitante. 


\section{Conclusiones}

Lomas de Primavera es un recurso natural ubicado en el distrito de Carabayllo, departamento de Lima, capital del Perú, de vital importancia turística, en especial para los habitantes del Asentamiento Humano Primavera. En ese sentido, la investigación tiene por objetivo determinar la conciencia turística de los pobladores de este lugar, considerando que supone promover e incrementar la preservación del patrimonio y servicios que posee una comunidad. La exploración se realiza en tres categorías: conocimiento, valores y actitudes.

Se determina que los pobladores del Asentamiento Humano Primavera conocen su recurso natural, reconocen su potencial y su belleza que atrae a turistas y visitantes de distintas edades, nivel educativo, condición socioeconómica, etc., puesto que se involucran en el cuidado y preservación del lugar, participando en charlas, que se dan de manera continua por la Municipalidad de Carabayllo y otras instituciones. Asimismo, expresan su deseo por contar con ingresos económicos producto de las visitas; razón por la cual los pobladores plantean crear servicios de alimentación y de higiene, ya que han observado que carecen de estos y que son muy requeridos por los visitantes. Por consiguiente, ellos demuestran practicar sus valores al ser responsables, honestos y mostrar respeto con el turista.

Conociendo las características, los atractivos y las dificultades en este atractivo turístico pueden trabajar coordinadamente para lograr un desarrollo sustentable y sostenible. Tienen datos específicos como las épocas de verdor, la variedad de flora y fauna, los sectores de personas turistas y visitantes, etc. También, conocen como la invasión de terrenos y la contaminación afecta el ecosistema y están en contra de todo acto que contamine o destruya este atractivo lugar. En suma, los pobladores del Asentamiento Humano Primavera están decididos a preservar las Lomas de Primavera, mostrando una actitud comprometida y solidaria con el propio recurso natural y con quienes lo visitan. Consideran importante también, organizar actividades culturales y deportivas, como programas de rescate de flora y fauna, observación de ecosistemas, talleres de educación ambiental, trekking, ciclismo y más, en un recurso natural de atractivo turístico dentro de la ciudad de Lima.

Finalmente, es recomendable realizar más investigaciones para establecer, por ejemplo, la relación entre la afluencia turística y la práctica del ecoturismo en Lomas de Primavera y así contar con opciones creativas para la conservación del medioambiente, dentro del marco de los Objetivos del Desarrollo Sostenible (ODS), que «constituyen un llamamiento universal a la acción para poner fin a la pobreza, proteger el planeta y mejorar las vidas y las perspectivas de las personas en todo el mundo (Naciones Unidas, 2018, p. 1).

\section{Conflicto de intereses}

Los autores no tienen conflicto de intereses con el contenido de este trabajo.

\section{Contribución de autoría}

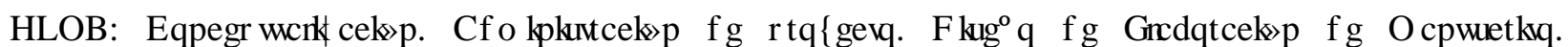

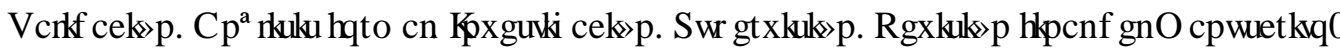

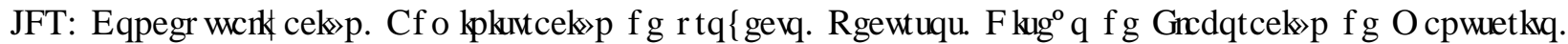

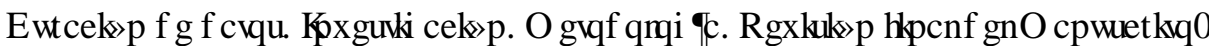

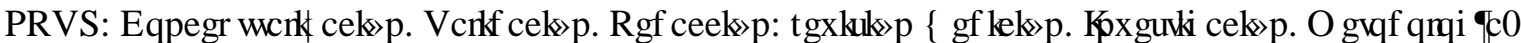




\section{Referencias}

Alto Comisionado de las Naciones Unidas para los Refugiados - UNHCR. (2016, julio). Fundamentos y evolución del concepto de «conciencia social». https://eacnur.org/blog/fundamentos-evolucion-del-concepto-conciencia-social/\#: :text=Entendemos\%20por\% 20conciencia\%20social\%20la,entidad\%2C\%20grupo\%20social\%20o\%20tribu

Baena, G. (2017). Metodologia de la investigación. Serie integral por competencias (3a ed.). Grupo Editorial Patria. http:// www.biblioteca.cij.gob.mx/Archivos/Materiales_de_consulta/Drogas_de_Abuso/Articulos/metodologia\%20de\%20la\% 20investigacion.pdf

Bellido, R. (2017). Conciencia Turística en los pobladores de las Lomas del Paraíso en Villa María del Triunfo 2018 [Tesis para lincenciatura, Universidad César Vallejo]. https://repositorio.ucv.edu.pe/bitstream/handle/20.500.12692/36548/ Bellido_MRM.pdf?sequence=1\&isAllowed=y

Bertoncello, V. R. y Troncoso, A. C. (2018). Vínculos entre patrimonio natural y turismo: una revisión para el caso argentino. Pasado Abierto, 4(8). https://fh.mdp.edu.ar/revistas/index.php/pasadoabierto/article/view/2867/5030

Cabana, A. F. (2017). Conciencia ambiental, valores y ecoeficiencia en la Gerencia de Servicios a la ciudad y medio ambiente Lima Cercado [Tesis doctoral, Universidad Cesar Vallejo]. Lima. https://repositorio.ucv.edu.pe/bitstream/handle/20.500.12692/4373/ Cabana_UAF.pdf?sequence=1\&fbclid=IwAR1ka9D5A1pZ7N_uOJWJqSQPYBDaqALO7i31c99mw2N7IUnpZoPi-OzLxrc

Castro, J. C. (2002). Análisis de los componentes actitudinales de los docentes hacia la enseñanza de la matemática. Caso: $1^{a}$ y $2^{a}$ etapas de Educación Básica [Tesis doctoral, Universitat Rovira i Virgili]. https://www.tdx.cat/handle/10803/8906\#page=1

Ciliane, C., Zamberian, N. y Flores, V. (2014). La valoración de las artesanías en el Sur de Brasil a través del turismo. Estudios y Perspectivas en Turismo, 23(4), 668-684. https://www.redalyc.org/articulo.oa?id=1807/180732145002

Díaz, J. y Fuentes, F. (2018). Desarrollo de la conciencia ambiental en niños de sexto grado de Educación Primaria. Significados y percepciones. Rev. Investig. Educ., 26, 136-163. http://www.scielo.org.mx/scielo.php?script=sci_arttext\&pid=S187053082018000100136

Díaz, R. y Gutiérrez, D. (2010). La actitud del residente en el destino turístico de Tenerife: Evaluación y Tendencia. PASOS Revista de Turismo y Patrimonio Cultural, 8(4), 431-444. https://doi.org/10.25145/j.pasos.2010.08.039

Ferrero, B. G. (2018). Tras una definición de las áreas protegidas. Apuntes sobre conservación de la naturaleza en Argentina. Revista Universitaria de Geografía, 27(1), 98-110. https:/www.redalyc.org/journal/3832/383257036006/383257036006.pdf

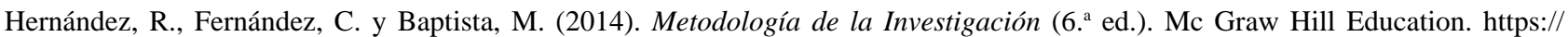
www.uca.ac.cr/wp-content/uploads/2017/10/Investigacion.pdf

La Riva, I. (2017, 9 de mayo). Conciencia turística y orgullo por lo nuestro. Blog de Sostenibilidad UPN. https://blogs.upn.edu.pe/ negocios/conciencia-turistica-y-orgullo-por-lo-nuestro/

Mendoza, O., Rodriguez, M. y Enciso, S. (2013). Actitud de la comunidad local como factor de éxito. Cultur, Revista de Cultura e Turismo, 7(1), 4-30. https://dialnet.unirioja.es/descarga/articulo/5322242.pdf

Mendoza, M. M., Alejo, M. y Rivera, R. (2018). La tolerancia del turismo y la transformación de una fiesta tradicional: actitudes de la población local. Investigaciones Turísticas,16, 127-142. https://rua.ua.es/dspace/bitstream/10045/84551/1/InvestigacionesTuristicas_16_07.pdf

Ministerio de Comercio Exterior y Turismo - Mincetur. (2016). Plan estratégico nacional de turismo del Perú - PENTUR. https:// www.gob.pe/institucion/mincetur/informes-publicaciones/22123-plan-estrategico-nacional-de-turismo-del-peru-pentur

Ministerio de Comercio Exterior y Turismo - Mincetur. (2019). Programa Municipal de Educación, Cultura y Ciudadanía Ambiental - EDUCCA. https://www.gob.pe/institucion/minam/campa\%C3\%B1as/130-programa-municipal-de-educacion-cultura-y-ciudadaniaambiental-educca

Mireles, A. (2015). Turismo: La concientización turística una tarea pendiente. AT Academia de Turismo. https://www.academia.edu/ 19434046/Turismo_La_Concientizaci\%C3\%B3n_Tur\%C3\%ADstica_una_Tarea_Pendiente

Molano, O. L. (2007). Identidad cultural, un concepto que evoluciona. Revista Opera, 7, 69-84. https://dialnet.unirioja.es/servlet/ articulo?codigo=4020258\#: :text=Molano\%20aporta\%20a\%20la\%20discusi\%C3\%B3n,el\%20humano\%20y\%20el\%20patrimonial. 
Naciones Unidas. (2018). La Agenda 2030 y los Objetivos de Desarrollo Sostenible: una oportunidad para América Latina y el Caribe. https://repositorio.cepal.org/bitstream/handle/11362/40155/24/S1801141_es.pdf

Ordenanza N. ${ }^{\circ}$ 1651, Aprueban Plan Específico de Lomas de Carabayllo. (8 de enero de 2013). Diario Oficial El Peruano, 12 de enero de 2013. https://busquedas.elperuano.pe/normaslegales/aprueban-plan-especifico-de-lomas-de-carabayllo-ordenanza-n-1651887333-1/

Ordenanza N. ${ }^{\circ}$ 345-2016-MDI, Declara de interés distrital, la intangibilidad, de interés patrimonial-cultural y de protección paisajística al ecosistema frágil denominado «Loma de Amancaes - Bella Durmiente» en el sector correspondiente al distrito Independencia. (16 de agosto de 2016). Diario Oficial del Bicentenario El Peruano. https://busquedas.elperuano.pe/normaslegales/ordenanza-quedeclara-de-interes-distrital-la-intangibilida-ordenanza-n-345-2016-mdi-1428656-1/

Ordenanza N. ${ }^{\circ}$ 397-2018-MDC, Declaran de interés distrital la intangibilidad, de interés patrimonial - cultural y de protección paisajística al ecosistema frágil denominado Lomas de Primavera - Lomas de Carabayllo. (26 de Abril de 2018). https://busquedas.elperuano.pe/ normaslegales/declaran-de-interes-distrital-la-intangibilidad-de-interes-ordenanza-no-397-2018-mdc-1662698-1/

Orellana, J. A. y Lalvay, T. (2018). Uso e importancia de los recursos naturales y su incidencia en el desarrollo turístico. Caso Cantón Chilla, El Oro, Ecuador. Revista Interamericana de Ambiente y Turismo, 14(1), 65-79. https://scielo.conicyt.cl/pdf/riat/v14n1/0718235X-riat-14-01-00065.pdf

Organización Mundial del Turismo - OMT. (2017, 22 de agosto). La OMT lleva a cabo la campaña «Travel.Enjoyy.Respect» [Viaja, disfruta y respeta]. https://www.unwto.org/es/la-omt-lleva-cabo-la-campana-travelenjoyrespect-0

Programa de las Naciones Unidas para el Desarrollo - PNUD. (2017, 3 de noviembre). Lomas de Carabayllo: último vestigio de área verde en Lima Norte, en riesgo de perderse. https:/www.pe.undp.org/content/peru/es/home/presscenter/articles/2017/11/03/lomasde-carabayllo-ltimo-vestigio-de-rea-verde-en-lima-norte-en-riesgo-de-perderse.html

Programa de las Naciones Unidas para el Desarrollo - PNUD. (2018, febrero). Proyecto Eba Lomas. Retos y oportunidades en las conservación de las Lomas de Lima Metropolitana. https:/www.undp.org/content/dam/peru/docs/Publicaciones\%20medio\%20ambiente/ Brochure_24PP_FINAL.pdf

Ramírez, M. (1994). Deontología y conciencia turística. https://www.entornoturistico.com/wp-content/uploads/2018/04/Deontologiay-conciencia-tur\%C3\%ADstica-de-Manuel-R.-Blanco.pdf

Servicio Nacional de Turismo - SERNATUR. (2013). Gestión 2012 Direcciones Regionales SERNATUR [Gobierno de Chile]. https:// www.sernatur.cl/wp-content/uploads/2018/08/cuentas_publicas_regiones_2012.pdf

Servicio Nacional de Turismo - SERNATUR. (2016). Programa de Conciencia Turística (Informe de Gestión 2016). https://biblioteca. sernatur.cl/documentos/153.796.16S491i.2017.pdf

Tonello, G. y Valladares, N. (2015). Conciencia ambiental y conducta sustentable relacionada con el uso de energía para iluminación. Gestion y Ambiente, 18(1), 45-59. https:/www.redalyc.org/pdf/1694/169439782003.pdf

Tobar, L. E., Castillo, M., Mendoza, R. y Tamayo, A. L. (2015). La visión crítica en el construir del conocimiento turístico. Revista de Análisis Turísticos, 19, 33-34. https://dialnet.unirioja.es/servlet/articulo?codigo=5169973

Urteaga, L. (1999). Sobre la noción de recurso natural. Publicacions Universitat de Barcelona (pp. 441-454). http://www.ispel3.edu.ar/ _paginas/biblioteca/materiales/geografia/varela_2do_geograf_1.pdf 
Heber Luis Olavarria Benavides

Universidad de San Martín de Porres, Perú.

Licenciado en Administración Turística y Hotelera con un Máster en Biodiversidad, Paisajes y Gestión Sostenible por la Universidad de Navarra, España y con una especialización en Proyectos de Inversión Pública en la Universidad del Pacífico. Con más de 11 años de experiencia profesional en instituciones públicas y privadas. Participa en la formulación y ejecución de proyectos de inversión en turismo, así como elabora inventarios de recursos turísticos a nivel nacional. Catedrático de la Escuela Profesional de Administración y Servicios Turísticos de la Universidad Privada del Norte y del Centro de Formación en Turismo (CENFOTUR)

heber_olavarria@usmp.pe

ORCID: https://orcid.org/0000-0002-3107-7778

Jackelyn Fernández Tello

Universidad Privada del Norte, Perú.

Bachiller en Administración y Servicios Turísticos por la Universidad Privada del Norte, Perú.

jackelynfernandezt@gmail.com

ORCID: https://orcid.org/0000-0002-6497-0060

Percy Ronald Ventura Suclupe

Universidad Nacional Pedro Ruiz Gallo, Perú.

Comunicador Social con Máster en Investigación en Comunicación por la Universidad de Navarra, España. Con más de 5 años de experiencia profesional. Catedrático de la Escuela Profesional de Ciencias de la Comunicación de la Universidad Nacional Pedro Ruiz Gallo, Perú. Publicación reciente (2017) «Tratamiento informativo de los delitos cometidos por menores» DOI: 10.5209/ESMP.58029.

pventurasuc@unprg.edu.pe

ORCID: https://orcid.org/0000-0002-7141-883X 


\section{Anexo 1}

Resumen de las entrevistas a los 35 pobladores del Asentamiento Humano Primavera.

\begin{tabular}{ccc}
\hline $\mathrm{N}^{\circ}$ & Nombre & Resumen \\
\hline 1 & Patricia Espinoza & Lomas de Primavera es un recurso importante que cuidar, sostiene, porque es \\
& una riqueza para el medioambiente. El mayor problema que enfrenta es el tráfico \\
& de terrenos. El turismo genera empleo local, lo que es favorable la familia ya que \\
& pueden dedicarse a la venta de productos. Considera necesario ser amable con \\
& los turistas y trabajar con los pobladores y autoridades participando de charlas, \\
& actividades recreativas, capacitaciones y limpieza de residuos sólidos.
\end{tabular}

2 Ascencio Vásquez

3 César Vega

4 Eugenio Livia

5 Alonso Poma

6 Asunta Navarrete Vargas

7 Jessica Huanca
El tema ambiental es importante, valora la flora y fauna de las lomas. Como ciudadano considera falta de concientización en los pobladores. Cree que las lomas mejoran la calidad de vida debido a su beneficio social, razón por la cual es amable con los turistas. Además, se reúne con el comité para hablar sobre futuros beneficios económicos y participa en la reforestación y la instalación de biohuertos.

Lomas de Primavera tiene importancia en el tema turístico, señala, por la llegada de turistas y estudiantes al lugar para informarse sobre este recurso natural. El tráfico de terrenos es algo serio que se debe combatir, ya que las lomas generan empleo local atrayendo a visitantes; el principal beneficio para él y su familia es el tema ambiental. Es atento con los turistas y tiene como objetivo cuidar y proteger las lomas participando en actividades de cuidado al medioambiente. En un futuro, desea establecer un hotel o restaurante cerca al sitio turístico. Pide a los visitantes no arrojar desperdicios y mantenerlo limpio.

El tema turístico es fundamental, señala; en cambio, el tráfico de terrenos es algo que debe combatirse y sucede en el presente. Para el entrevistado, la venta de productos le genera ingresos en su economía. Además, en lo cultural, ha logrado que sus nietos puedan aprender a valorar Lomas de Primavera. Es por eso que él suele ser muy servicial con los turistas y fomentar el cuidado no dañando las plantas y haciendo limpieza.

Resalta el tema ambiental como uno de los más importantes en Lomas de Primavera, no obstante, la contaminación juega un papel en contra ya que algunas personas no toman conciencia de cuidar este recurso natural. Pide a sus vecinos que sean receptivos con los visitantes y que la cuiden; promueve la participación en actividades de protección al medioambiente para beneficio económico y cultural de ellos mismos.

Comenta la belleza paisajística que posee Lomas de Primavera, gracias al verdor de su paisaje en épocas de invierno y la variedad de plantas que crecen. De igual forma, la entrevista contribuye al cuidado, reuniéndose con el comité, junto con su familia, participando en actividades como la reforestación.

La importancia ambiental en Lomas de Primavera es cada vez más popular entre los pobladores del Asentamiento Humano Primavera, sostiene, ya que cada fin de mes estudiantes de muchas escuelas y universidades llegan al sitio. La entrevistada comenta que siempre muestra una actitud servicial cuando un turista le hace alguna pregunta. Para ella, gracias a estas lomas ha logra vender sus productos artesanales como llaveritos y collares; por esa razón, sigue participando en actividades culturales que organizan instituciones como EbA Lomas. 


\begin{tabular}{cll}
\hline N. & Nombre & \multicolumn{1}{c}{ Resumen } \\
\hline $8 \quad$ Enrique Santos & $\begin{array}{l}\text { El tema ambiental es importante cuando se trata de Lomas de Primavera. El mayor } \\
\text { problema es la contaminación; cree que el valor cultural de las lomas lo ayudan a } \\
\text { comprender mejor la situación de los recursos naturales y turísticos. Se } \\
\text { compromete a diario en cuidarla y protegiéndola con la limpieza de los residuos } \\
\text { sólidos. }\end{array}$
\end{tabular}

9 Marcos Jarana

10 César Clemente

11 Nicole Retuerto

12 Jorge Luis Ramírez

13 Carlos Loayza

14 Estefany Miranda

15 Mario Quispe

16 Sebastián Ayala

17 María Flor Muñoz

18 Daniel Chipana

19 Yanina Chambi
La importancia turística es lo que más destacadas y el mayor problema es tráfico de terrenos, que es una amenaza constante. Por ello, participa en capacitaciones que se realizan con el fin de concientizar a los pobladores en la defensa y cuidado de Lomas de Primavera.

Admira la belleza paisajística de Lomas de Primavera, pese a la contaminación que algunas personas realizan por no tener conciencia turística, señala. Desconoce la existencia de tráfico de terrenos en la zona. Gracias a las charlas, está comprometido a colaborar en mejorar el lugar y mostrándose amable con los visitantes.

Destaca la belleza paisajística y el beneficio turístico de Lomas de Primavera; considera que si son receptivos con los turistas el lugar se hará conocido y tendrán ganancias.

Destaca la belleza paisajística como lo más importante. Es amable con los visitantes. Participa en actividades de limpieza de residuos sólidos y fomenta el cuidado de Lomas de Primavera.

El tema ambiental ayuda a los pobladores sostiene; siente que puede aprovechar Lomas de Primavera como un medio para generar ingresos. Es por eso que asiste a charlas y participa en la reforestación.

Para la entrevistada la belleza paisajística de Lomas de Primavera es lo más importante. El tráfico de terrenos es perjudicial. Piensa que puede aprovechar este recurso natural trabajando como guía turística, mejorando así su calidad de vida.

Señala que se puede conservar la flora y fauna conociendo la importancia que se tiene. Aprendió esto debido a las reuniones con el comité y a su vez participando en actividades culturales.

Destaca la belleza paisajística como lo más importante. A pesar del tráfico de terrenos, el turismo en Lomas de Primavera es más fuerte y se hace conocido el lugar; también señala, que puede ganar dinero con venta de productos locales. Por esa razón, muestra una actitud servicial con los visitantes.

Lomas de Primavera tiene importancia turística, considera, porque atrae a muchas personas. Cuenta que participa en charlas para tomar conciencia en el cuidado de este recurso natural. Es una oportunidad para generar una mejor economía que beneficie a los pobladores.

La riqueza ambiental es su mayor atributo de Lomas de Primavera. Relata que los fines de semana acude para relajarse y tomar aire fresco. Desea construir, en el lugar, un hotel o restaurante para poder generar beneficios económicos en su hogar.

La belleza paisajística es de vital importancia para los pobladores del Asentamiento Humano Primavera sostiene la entrevistada. Considera que las Lomas están abandonadas, por eso desea aprender sobre el cuidado para generar una actitud consciente en sus hijos y sus vecinos. Es por eso que participa en capacitaciones. 


\begin{tabular}{lll}
\hline $\mathrm{N} .{ }^{\circ}$ & Nombre & \multicolumn{1}{c}{ Resumen } \\
\hline 20 & Kevin Huamán & $\begin{array}{l}\text { El tema ambiental ayuda a tomar conciencia para conservarla y para mejorar la } \\
\text { calidad de vida. Debido a su participación en las actividades sobre el } \\
\text { medioambiente, tiene una actitud más consciente. Es por eso que considera una } \\
\text { buena decisión trabajar con los pobladores y las autoridades para proteger Lomas } \\
\text { de Primavera. }\end{array}$
\end{tabular}

21 Alex Pinto

22 José Angulo

23 Ángel Olaya

24 Alberto Cano

25 Eduardo Sulca

26 Rosa Campo

27 David Villanueva

28 Flor Vilca

29 Isabel Chumbe

30 Sara Vara

31 Illari Flores
La belleza paisajística es importante para el entrevistado, debido a que se siente agradecido de vivir cerca de las lomas. Se ha percatado de la acogida que Lomas de Primavera tiene de parte de estudiantes, principalmente. Considera como beneficio las actividades recreativas para pasar tiempo con la familia.

La importancia ambiental la destaca; cree que uno de los beneficios es que contribuye a mejorar la zona, por eso, participa en capacitaciones y en la creación de un vivero para un colegio.

Señala importancia turística. Tiene conocimiento que en la zona ocurre tráfico de terrenos. La actividad turística en Lomas de Primavera puede contribuir con la generación de empleo local, atrayendo visitantes, mejorando así el aspecto ambiental para los pobladores y su familia, les permitiría gozar de una maravilla natural bien cuidada cerca a su casa.

El tema ambiental es lo más importante. Considera que el turismo genera ingresos con la venta de productos locales. A pesar de no participar de ninguna actividad desea instalar un hotel para generar ingresos económicos y apoyar a su familia.

La belleza paisajística es de suma importancia para el entrevistado, quien contribuye con el cuidado de las Lomas de Primavera, asegurándose de no dañar las plantas, participando en la creación de un vivero y siendo receptivo con los visitantes para que se lleven una buena imagen del lugar.

Destaca la belleza paisajística.

Belleza paisajística es lo que posee Lomas de Primavera y se destaca principalmente por ello. El tráfico de terrenos es una amenaza; es responsable a la hora de cuidar las Lomas. Participa en las charlas y capacitaciones que se dan con el fin de salvaguardar la zona y aprender más sobre el turismo.

Lomas de Primavera tiene su mayor atractivo en el paisaje, la flora y la fauna que posee. Gracias a ello se puede generar ingresos con las visitas, lo que redundaría en mejora de la zona. Para la entrevistada la actividad turística es beneficiosa, contribuye al bienestar y a la educación de sus hijos.

Belleza paisajística se destaca como un factor importante debido a las Lomas, se genera empleo local con las visitas a las lomas. El beneficio es económico, por eso quiere implementar una tienda de recuerdos del lugar.

La parte turística es una de las ventajas sostiene, es consciente de ello, ya que su actitud es receptiva fomentando en sus hijos el cuidado de las Lomas de Primavera, participando en la reforestación y con el vivero del colegio.

Desconoce amenazas que enfrenta Lomas de Primavera, no obstante, es consciente que el turismo genera empleo local para ella y sus vecinos. Ella aprovecha esto para vender sus productos locales mostrándose respetuosa con los visitantes. 


N. Nombre $\quad$ Resumen

32 Gabriela Arroyo

33 Guillermina Huyhua

34 Rosa Sandoval

35 Esther Valverde
El tema más importante es el ambiental dentro de las lomas, a pesar de no conocer sobre los problemas que presentan, es consciente que el turismo genera una mejor calidad de vida y con ello beneficiarse socialmente.

El turismo es una ventaja porque atrae visitantes de diferentes partes. Ella desea contar, en un corto plazo, con un restaurante. Participó en la creación de un vivero en un colegio.

Resalta la belleza paisajística de Lomas de Primavera. Considera que existe contaminación. El beneficio de las lomas, según señala, es cultural, por eso las cuida y protege, ya que en un futuro desea implementar su tienda de souvenirs.

El tema turístico es importante ya que genera empleo local. Asimismo, muestra actitud amable. Enseña a los pobladores y los invoca a no botar residuos sólidos. Participa en actividades sobre el medioambiente y biohuertos. 